\title{
Metabolite Profiles of Red and Yellow Watermelon (Citrullus lanatus) Cultivars Using a ${ }^{1} \mathrm{H}-\mathrm{NMR}$ Metabolomics Approach
}

\author{
Fadzil Sulaiman ${ }^{1}{ }^{\mathbb{D}}$, Amalina Ahmad Azam ${ }^{1}$, Muhammad Safwan Ahamad Bustamam ${ }^{1}$, \\ Sharida Fakurazi ${ }^{2}$, Faridah Abas ${ }^{1}$ (D), Yee Xuan Lee ${ }^{1}$, Atira Adriana Ismail ${ }^{1}$, \\ Siti Munirah Mohd Faudzi ${ }^{1}$ and Intan Safinar Ismail ${ }^{1, *(D)}$ \\ 1 Laboratory of Natural Products, Institute of Bioscience, Universiti Putra Malaysia, Serdang 43400, Malaysia; \\ mfadzilsulaiman90@gmail.com (F.S.); amalina_azam@hotmail.com (A.A.A.); \\ safwan.upm@gmail.com (M.S.A.B.); faridah_abas@upm.edu.my (F.A.); leeyeexuan0613@gmail.com (Y.X.L.); \\ atiradriana@gmail.com (A.A.I.); sitimunirah@upm.edu.my (S.M.M.F.) \\ 2 Laboratory of Vaccines and Immunotherapeutics, Institute of Bioscience, Universiti Putra Malaysia, Serdang \\ 43400, Malaysia; sharida@upm.edu.my \\ * Correspondence: safinar@upm.edu.my; Tel.: +60-3-9769-7492
}

Academic Editor: Ewa Sikorska

Received: 20 May 2020; Accepted: 5 June 2020; Published: 15 July 2020

\begin{abstract}
Watermelon, a widely commercialized fruit, is famous for its thirst-quenching property. The broad range of cultivars, which give rise to distinct color and taste, can be attributed to the differences in their chemical profile, especially that of the carotenoids and volatile compounds. In order to understand this distribution properly, water extracts of red and yellow watermelon pulps with predominantly polar metabolites were subjected to proton nuclear magnetic resonance $\left({ }^{1} \mathrm{H}-\mathrm{NMR}\right)$ analysis. Deuterium oxide $\left(\mathrm{D}_{2} \mathrm{O}\right)$ and deuterated chloroform $\left(\mathrm{CDCl}_{3}\right)$ solvents were used to capture both polar and non-polar metabolites from the same sample. Thirty-six metabolites, of which six are carotenoids, were identified from the extracts. The clustering of the compounds was determined using unsupervised principal component analysis (PCA) and further grouping was achieved using supervised orthogonal partial least squares discriminant analysis (OPLS-DA). The presence of lycopene, $\beta$-carotene, lutein, and prolycopene in the red watermelon plays an important role in its differentiation from the yellow cultivar. A marked difference in metabolite distribution was observed between the NMR solvents used as evidenced from the PCA model. OPLS-DA and relative quantification of the metabolites, on the other hand, helped in uncovering the discriminating metabolites of the red and yellow watermelon cultivars from the same solvent system.
\end{abstract}

Keywords: ${ }^{1} \mathrm{H}-\mathrm{NMR}$; Citrullus lanatus; varieties; discriminants; carotenoids

\section{Introduction}

Chemometrics is a tool which utilizes mathematical and statistical models in gathering information from a chemical system. With the advancement of computer science, raw chemical data can be remodeled to derive patterns or new variables to address problems in the field of pharmaceutical science [1], biochemistry [2], medicine [3], natural product research [4], and agriculture [5]. This approach helps in the handling of large sets of data such as those of the omics in understanding a biological system or process.

The visualization and clustering of spectral input by means of multivariate data analysis (MVDA) assist in the assessment of biochemical processes of a complex set of phenotypes [6]. In the metabolomics analysis of a plant, the effect of a particular environment or stressor on a species can be studied by the 
qualitative or quantitative measurement of its metabolites, such as those presented in the study of Nicotiana tabacum and Brassica rapa (L.) against infection and herbivory, respectively [7,8]. Integrative taxonomy, which incorporates metabolomics, has been suggested in overcoming the limitations of morphological and molecular classification of plants [9]. Interest in metabolome diversity of different cultivars of the same plant species is also gaining traction for the wealth of information it provides, as evidenced in the study of two Oryza sativa L. [10] and 43 Camellia sinensis L. cultivars [11].

The general goal of metabolomics studies in profiling and classifying plant metabolites by way of fingerprinting can be achieved by incorporating proton nuclear magnetic resonance $\left({ }^{1} \mathrm{H}-\mathrm{NMR}\right)$ analysis . This spectroscopic method allows the simultaneous identification of primary and species-specific secondary metabolites while permitting the comparison of their concentrations without the need of an individual calibration curve [12]. Having a general view of the metabolites with different polarity, behavior, and stability in just one experiment is advantageous in studies concerning the interaction between the phenotypes with the environment, although large sets of data are needed to ensure its reproducibility [13]. Other possible shortcomings of this approach, such as the limitation in metabolite identification from signal overlapping, are rapidly overcome with the incorporation of two-dimensional NMR. As for low sensitivity despite upgrades in the hardware used, approaches that optimize samples and pulse sequences, improve the electronics of the probe and coils, and increase the magnetic fields have been suggested to resolve this issue [14]. The interpretation and the search for new variables from large sets of ${ }^{1} \mathrm{H}-\mathrm{NMR}$ data can be accomplished using statistical interpretation such as principal component analysis (PCA), a technique which reduces data dimensionality while minimizing information loss [15]. Meanwhile, in the case of data grouping within a group, a supervised statistical method such as orthogonal partial least squares discriminant analysis (OPLS-DA) with a validation method can be utilized [16].

Watermelon or Citrullus lanatus (Thunb.) is a vine-like flowering plant belonging to the Cucurbitaceae family. Originating from the African continent, this fruit has been widely cultivated and is highly favored for its sweet and refreshing taste. Studies on the bioactivities have revealed that the presence of cucurbitacin E isolated from the pulp displayed a good anti-inflammatory activity through the inhibition of cyclooxygenase (COX) and reactive nitrogen species (RNS), whereas lycopene, $\beta$-carotene, and ascorbic acid contributed greatly to the fruit's antioxidant property [17,18]. Because interest in the health benefits of carotenoids has grown, it is worthwhile to look into watermelon cultivars that possess a wide range of this phytochemical group [19,20]. Aside from the reasons stated above, the decision in using a metabolomics approach was made since limited studies are available for this particular species. One study highlights the sugar and amino acid concentrations between two watermelon varieties and another explores the sensory quality between a watermelon grafted onto a gourd and onto pumpkin rootstocks [21,22]. Both studies did not report on the carotenoid profile.

Therefore, the aim of this study was to outline the metabolites present in the red and yellow watermelon cultivars via a metabolomics approach, with a special interest on the carotenoid group. Based on the color of the flesh, it can be deduced that both cultivars may give a different set of phytochemicals responsible for their pigments. However, the interaction between different groups of metabolites can also be conceptualized using a more analytical approach. The results obtained from this study can be used to better understand the biochemical process of this fruit in addition to the advantage of correlating the identified metabolites to their medicinal values to tailor one's dietary intake.

\section{Results and Discussion}

Carotenoids, known as tetraterpenes, are a group of natural products with a carbon-40 skeleton. These phytochemicals give a strong pigment as a result of their highly conjugated carbons, and the color produced is known to have a protective effect against ultraviolet (UV) rays and free radicals [23]. The reported carotenoids in the red watermelon are predominantly lycopene with trace amounts of phytoene, phytofluene, $\zeta$-carotene, $\alpha$-carotene, lutein, zeaxanthin, and violaxanthin, whereas those 
of the yellow watermelon are neoxanthin, violaxanthin, and neochrome [24-26]. Other common metabolite groups that are found in watermelons include sugars (glucose, sucrose, and fructose), amino acids (isoleucine, valine, citrulline, arginine, and glutamine), organic acids (malic acid, citric acid, quinic acid, and tartaric acid), and a set of volatile compounds [22,25]. As for its nutritional value, a $100 \mathrm{~g}$ portion of watermelon contains about $91 \%$ water, $6 \%$ sugar and $0.4 \%$ fiber. Potassium, phosphorus, magnesium, calcium, and ascorbic acid are among the micronutrients which are abundant in the fruit, making it a healthy dietary choice [27]. Due to the lack of ${ }^{1} \mathrm{H}-\mathrm{NMR}$ data for the identification of metabolites in watermelons, profiling was done using Chenomx software (v.5.1, Edmonton, AB, Canada) and by comparing the chemical shifts of the spectra with the ones from previously reported literature [28-30].

\subsection{H-NMR of the Pulp Extracts of Red and Yellow Watermelon Cultivars}

In this research, the extraction of watermelon pulp was done using Millipore water to mimic dietary intake. Ultrasonication was chosen for the extraction technique as this maximized the yield of lycopene as shown in a study involving tomatoes [31]. This may be true for other metabolites as well, for the agitation and cell wall breakdown help to release the metabolites from their cellular condition. Carotenoids can be divided into non-oxygenated carotenes and oxygenated xantophylls, the former being more orange in color while the latter is yellow. Both exist abundantly in an average diet of a person, especially from the fruits and vegetables. Due to the metabolites' lipophilic nature, the water extract was subjected to NMR analysis using two types of solvents, namely deuterium oxide $\left(\mathrm{D}_{2} \mathrm{O}\right)$ and deuterated chloroform $\left(\mathrm{CDCl}_{3}\right)$, to capture the metabolites present in both extremes of the polarity scale. A total of 36 metabolites were identified from the samples as shown in Table 1, of which 27 are from the $\mathrm{D}_{2} \mathrm{O}$ solvent and the remaining 9 from $\mathrm{CDCl}_{3}$. Compounds such as methionine and lysine, from a previously reported metabolomics study of watermelons, were not able to be profiled [21]. This is probably due to the difference in cultivar types [21], harvest time [32], sample processing method [33], or even from the overlapping of signals in the ${ }^{1} \mathrm{H}-\mathrm{NMR}$ spectra [13].The same applies to the unidentified carotenoids such as phytoene, phytofluene, $\zeta$-carotene, $\alpha$-carotene, neoxanthin, and neochrome, which were reported in other studies [24-26]. Despite the limitations in the detection of some metabolites, no metabolomics study has highlighted the color difference of the watermelon cultivars' flesh as presented in the current report.

Table 1. Identified metabolites in red and yellow watermelon cultivars using two types of nuclear magnetic resonance (NMR) solvent (R: red watermelon, Y: yellow watermelon, W: deuterium oxide, C: deuterated chloroform).

\begin{tabular}{|c|c|c|c|c|c|c|}
\hline No. & Metabolite & Chemical Shift (Multiplicity) & RW & YW & RC & YC \\
\hline 1 & $\alpha$-Glucose & $5.23(\mathrm{~d}, J=4.0 \mathrm{~Hz})$ & + & + & - & - \\
\hline 2 & $\beta$-Glucose & $4.64(\mathrm{~d}, J=8.0 \mathrm{~Hz})$ & + & + & - & - \\
\hline 3 & Sucrose & $5.41(\mathrm{~d}, J=4.0 \mathrm{~Hz})$ & + & + & - & - \\
\hline 4 & Fructose & $4.22(\mathrm{~d}, J=9.0 \mathrm{~Hz})$ & + & + & - & - \\
\hline 5 & Alanine & $1.48(\mathrm{~d}, J=7.5 \mathrm{~Hz})$ & + & + & - & - \\
\hline 6 & Glutamine & $2.14(\mathrm{~m}), 2.47(\mathrm{~m})$ & + & + & - & - \\
\hline 7 & Arginine & $3.76(\mathrm{~m}), 1.89(\mathrm{~m}), 1.63(\mathrm{~m}), 3.24(\mathrm{t}, J=9.0 \mathrm{~Hz})$ & + & + & - & - \\
\hline 8 & Threonine & $1.33(\mathrm{~d}, J=7.0 \mathrm{~Hz})$ & + & + & - & - \\
\hline 9 & Tryptophan & $\begin{array}{c}7.20(\mathrm{t}, J=7.0 \mathrm{~Hz}), 7.29(\mathrm{t}, J=8.0 \mathrm{~Hz}), 7.32(\mathrm{~s}), 7.54 \\
(\mathrm{~d}, J=8.0 \mathrm{~Hz}), 7.74(\mathrm{~d}, J=8.0 \mathrm{~Hz})\end{array}$ & + & + & - & - \\
\hline 10 & Tyrosine & $7.19(\mathrm{t}, J=7.0 \mathrm{~Hz}), 6.90(\mathrm{~m})$ & + & + & - & - \\
\hline 11 & Valine & $0.99(\mathrm{~m}), 1.04(\mathrm{~d}, J=7.0 \mathrm{~Hz})$ & + & + & - & - \\
\hline 12 & Leucine & $3.72(\mathrm{t}, J=4.0 \mathrm{~Hz}), 0.93(\mathrm{~d}, J=7.5 \mathrm{~Hz}), 0.96(\mathrm{~m})$ & + & + & - & - \\
\hline
\end{tabular}


Table 1. Cont.

\begin{tabular}{|c|c|c|c|c|c|c|}
\hline No. & Metabolite & Chemical Shift (Multiplicity) & RW & YW & RC & YC \\
\hline 13 & Isoleucine & $1.01(\mathrm{~m}), 0.94(\mathrm{~m})$ & + & + & - & - \\
\hline 14 & Citrulline & $3.15(\mathrm{t}, J=7.0 \mathrm{~Hz}), 1.58(\mathrm{~m}), 3.76(\mathrm{~m})$ & + & + & - & - \\
\hline 15 & Acetate & $1.91(\mathrm{~s})$ & + & + & - & - \\
\hline 16 & Citrate & $2.50(\mathrm{~d}, J=8.0 \mathrm{~Hz}), 2.70(\mathrm{dd}, J=15.5,3.5 \mathrm{~Hz})$ & + & + & - & - \\
\hline 17 & Fumarate & $6.53(\mathrm{~s})$ & + & + & - & - \\
\hline 18 & Phenylalanine & $7.33(\mathrm{~m}), 7.39(\mathrm{~m}), 7.43(\mathrm{~m})$ & + & + & - & - \\
\hline 19 & 4-Aminobutyrate & $2.31(\mathrm{t}, J=7.5 \mathrm{~Hz}), 3.01(\mathrm{t}, J=7.5 \mathrm{~Hz})$ & + & + & - & - \\
\hline 20 & Malic acid & $\begin{array}{c}4.32(\mathrm{dd}, J=10.0,3.5 \mathrm{~Hz}), 2.70(\mathrm{dd}, J=15.5,3.5 \\
\mathrm{Hz}), 2.82(\mathrm{dd}, J=18.0,4.5 \mathrm{~Hz})\end{array}$ & + & + & - & - \\
\hline 21 & Aspartate & $\begin{array}{c}2.70(\mathrm{dd}, J=15.5,3.5 \mathrm{~Hz}), 2.82(\mathrm{dd}, 18.0,4.5 \mathrm{~Hz}) \\
3.90(\mathrm{dd}, J=10.5,3.5 \mathrm{~Hz})\end{array}$ & + & + & - & - \\
\hline 22 & Xylose & $3.39(\mathrm{t}, J=9.5), 4.54(\mathrm{~d}, J=19.5 \mathrm{~Hz}), 5.19(\mathrm{~m})$ & + & + & - & - \\
\hline 23 & Ascorbic acid & $4.54(\mathrm{~d}, J=19.5 \mathrm{~Hz})$ & + & + & - & - \\
\hline 24 & Linoleic acid & $0.88(\mathrm{~m}), 1.17(\mathrm{~m})$ & - & - & + & + \\
\hline 25 & Acetic acid & $1.97(\mathrm{~s})$ & - & - & + & - \\
\hline 26 & Succinic acid & $2.48(\mathrm{~s})$ & + & + & - & - \\
\hline 27 & Aspartic acid & $2.82(\mathrm{dd}, J=18.0,4.5 \mathrm{~Hz}), 2.65(\mathrm{~d}, 7.5)$ & + & + & - & - \\
\hline 28 & Cucurbitacin E & $6.08(\mathrm{~s}), 4.65(\mathrm{~d}, 8.0), 4.02(\mathrm{~m}), 2.07(\mathrm{~m})$ & + & + & - & - \\
\hline 29 & Formic acid & $8.51(\mathrm{~s})$ & + & + & - & - \\
\hline 30 & Gallic acid & $7.05(\mathrm{~s})$ & - & - & + & + \\
\hline 31 & Lycopene & $\begin{array}{c}\text { 6.17-6.68 (m), } 5.95(\mathrm{~m}), 5.11(\mathrm{bs}), 2.11(\mathrm{bs}), 2.00 \\
(\mathrm{bs}), 1.82(\mathrm{~s}), 1.68(\mathrm{~s}), 1.62(\mathrm{~s})\end{array}$ & - & - & + & - \\
\hline 32 & $\beta$-Carotene & $1.49(\mathrm{~s}), 1.62(\mathrm{~s}), 1.72(\mathrm{~s}), 2.03(\mathrm{~s}), 6.17(\mathrm{~s}), 6.19(\mathrm{~s})$ & - & - & + & - \\
\hline 33 & Lutein & $\begin{array}{c}6.36(\mathrm{~d}, J=15.0 \mathrm{~Hz}), 6.25(\mathrm{~d}, J=15.5 \mathrm{~Hz}), 1.97(\mathrm{~s}) \\
1.01(\mathrm{~s}), 0.87(\mathrm{~s})\end{array}$ & - & - & + & - \\
\hline 34 & Violaxanthin & $1.97(\mathrm{~s}), 1.95(\mathrm{~s}), 1.15(\mathrm{~s}), 0.94(\mathrm{~s})$ & - & - & + & + \\
\hline 35 & Zeaxanthin & $1.97(\mathrm{~s}), 1.98(\mathrm{~s}), 1.77(\mathrm{~s}), 1.07(\mathrm{~s})$ & - & - & + & + \\
\hline 36 & Prolycopene & $\begin{array}{c}5.09(\mathrm{~m}), 6.30(\mathrm{~m}), 6.47(\mathrm{~m}), 6.25(\mathrm{~d}, J=15.5 \mathrm{~Hz}) \\
1.64(\mathrm{~s}), 1.56(\mathrm{~s}), 1.97(\mathrm{~s})\end{array}$ & - & - & + & - \\
\hline
\end{tabular}

Positive (+) and negative (-) signs denote present and absent, respectively.

The representative ${ }^{1} \mathrm{H}-\mathrm{NMR}$ spectra for each sample are presented in Figures 1 and 2 (Figure S1). No notable difference is observed between the RW and YW samples except for the intensity of the peaks, which suggests the varying concentrations of the metabolites. A marked overlapping of signals is observed between 3.25 and $4.25 \mathrm{ppm}$, which limits the identification of metabolites from this region for both samples. The peaks of the sugars dominate the spectra and can be clearly seen between the region of 4.5-5.5 ppm. As for the $\mathrm{CDCl}_{3}$ samples, a marked difference is present in the region of 1.7-2.5 ppm, which explains the identification of acetic acid and lycopene peaks exclusively from the RC sample. However, not many peaks were identified in the low-field region, which is characteristic of the carotenoid group; this may be due to the principle of liquid-liquid extraction in which limited non-polar compounds are drawn out using the $\mathrm{CDCl}_{3}$ solvent from the predominantly polar group of metabolites concentrated in the water extracts. Multivariate data analysis using SIMCA-P software (v.14.1, Umetrics, Umeà, Sweden) was performed to obtain the principal component analysis (PCA) model to better understand the metabolite variation within the different groups. 


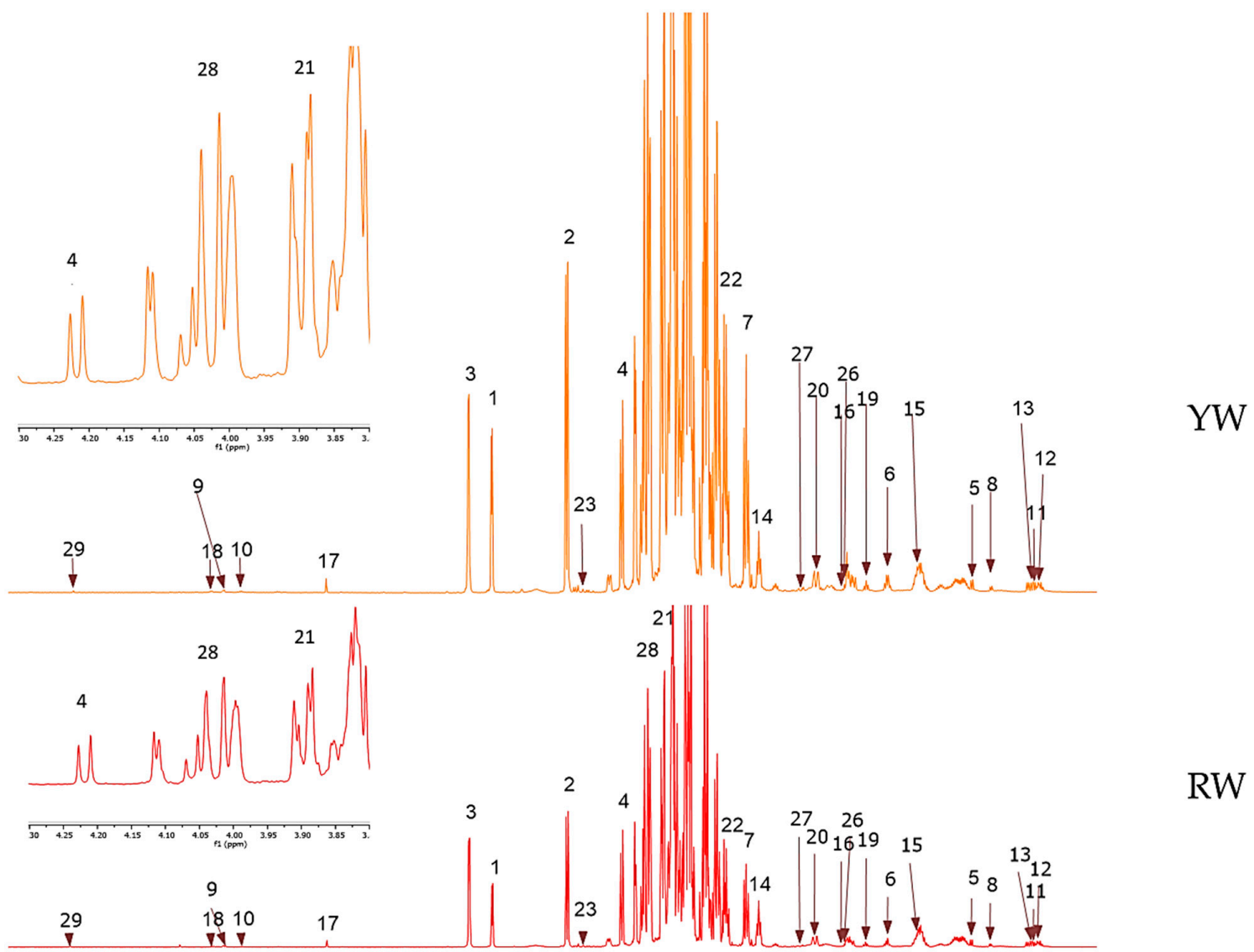

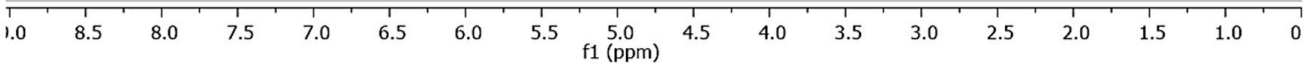

Figure 1. Representative ${ }^{1} \mathrm{H}-\mathrm{NMR}$ spectra of red watermelon (RW) and yellow watermelon (YW) in deuterium oxide $\left(\mathrm{D}_{2} \mathrm{O}\right)$; inset: $10 \times$ expansion of 3.80 to $4.80 \mathrm{ppm}$. Identified metabolites: (1) $\alpha$-Glucose, (2) $\beta$-Glucose, (3) Sucrose, (4) Fructose, (5) Alanine, (6) Glutamine, (7) Arginine, (8) Threonine, (9) Tryptophan, (10) Tyrosine, (11) Valine, (12) Leucine, (13) Isoleucine, (14) Citrulline, (15) Acetate, (16) Citrate, (17) Fumarate, (18) Phenylalanine, (19) 4-Aminobutyrate, (20) Malic acid, (21) Aspartate, (22) Xylose, (23) Ascorbic acid, (26) Succinic acid, (27) Aspartic acid, (28) Cucurbitacin E, (29) Formic acid.

\subsection{Multivariate Data Analysis of the Pulp Extracts of Red and Yellow Watermelon Cultivars}

Figure 3 shows the clustering based on the ${ }^{1} \mathrm{H}-\mathrm{NMR}$ data of the red and yellow watermelon cultivars analyzed in the $\mathrm{D}_{2} \mathrm{O}$ and $\mathrm{CDCl}_{3}$ solvents. Satisfactory goodness of fit and predictability are observed from the values of R2X and Q2X, which are 0.991 and 0.983 , respectively. This follows the criteria of a good model, i.e., Q2 $>0.5, \mathrm{R} 2>\mathrm{Q} 2$, and the difference between both values is between 0.2 to 0.3 [34]. A variation total of $98.2 \%$ is shown by the first two principal components with PC1 accounting for $95.4 \%$ and PC2 for $2.8 \%$. This gives rise to a good separation of the solvent groups by PC1, whereas the different watermelon cultivars extracted by the same solvent system, particularly $\mathrm{CDCl}_{3}$, seem to be clustered together. One distinct outlier is identified from the RW group; however, the data are included in the plot as its DModX value (Figure S2) is not twice as large as the maximum tolerable distance (Dcrit) value to be considered a moderate outlier. This was confirmed with its Hotelling's T2 value (Figure S3), which is lower than the confidence limits [34]. 


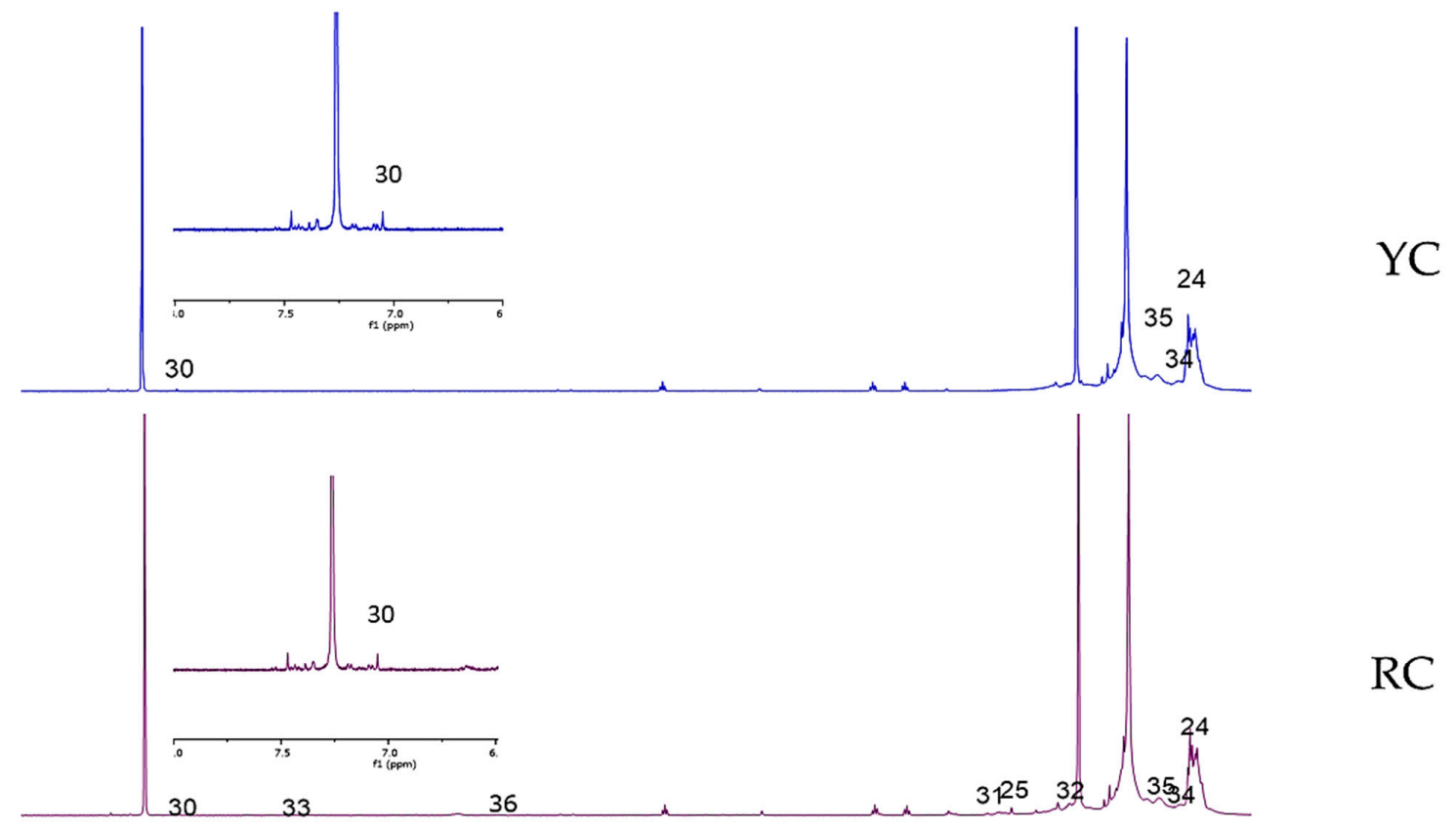

\begin{tabular}{llllllllllllllll}
\hline .0 & 7.5 & 7.0 & 6.5 & 6.0 & 5.5 & $\begin{array}{c}5.0 \\
\mathrm{f} 1(\mathrm{ppm})\end{array}$ & 4.5 & 4.0 & 3.5 & 3.0 & 2.5 & 2.0 & 1.5 & 1.0 & 0
\end{tabular}

Figure 2. Representative ${ }^{1} \mathrm{H}-\mathrm{NMR}$ spectra of red watermelon (RC) and yellow watermelon (YC) in deuterated chloroform $\left(\mathrm{CDCl}_{3}\right)$; inset: $2.5 \times$ expansion of the aromatic region from 6.50 to $8.00 \mathrm{ppm}$. Identified metabolites: (24) Linoleic acid, (25) Acetic acid, (30) Gallic acid, (31) Lycopene, (32) $\beta$-Carotene, (33) Lutein, (34) Violaxanthin, (35) Zeaxanthin, (36) Prolycopene.

PCA is often useful in exposing separation when the variation between the class is greater than within the class [16]. Where interest in both groups of variables is of concern, it is best to adopt a supervised modelling approach using orthogonal partial least squares discriminant analysis (OPLS-DA). Figure 4 shows the OPLS-DA performed on the ${ }^{1} \mathrm{H}$-NMR data of the red and yellow watermelon cultivars in the $\mathrm{D}_{2} \mathrm{O}$ and $\mathrm{CDCl}_{3}$ solvents (Figure $\mathrm{S} 4$ and S5); the data from both the solvent and cultivar groups are well separated. Satisfactory goodness of fit and predictability of this model are observed from the values of R2X and Q2X, which are 0.995 and 0.862, respectively [34]. The 100-permutation test and CV-ANOVA validation methods were used to nullify the risk of overfitting, which comes with a supervised statistical analysis. In the permutation test (Figure S6-S9), a model with a Y-axis intercept below 0.3 for R2 and 0.05 for Q2 and a non-horizontal R2 line is said to be reliable. These values are apparent for the 4 classes of data tested except for their R2 value, which is slightly above 0.3 . The CV-ANOVA test (Table S1), on the other hand, confirmed that the model is of optimum fit with the value of $1.22 \times 10^{-9}$, which is lower than the cut-off of 0.05 [34].

The OPLS-DA loading column plot, however, does not give rise to significant discriminated metabolites as the error bar for all of the columns crosses the $\mathrm{X}$-axis. Nevertheless, the model predicted that higher concentrations of tryptophan, fumarate, $\alpha$-glucose, $\beta$-glucose, malic acid, xylose, arginine, 4-aminobutyrate, glutamine, citrulline, and threonine in RW and phenylalanine, tyrosine, sucrose, fructose, cucurbitacin E, aspartate, leucine, aspartic acid, and alanine in YW differentiate both groups from one another. Meanwhile, higher concentrations of gallic acid, linoleic acid, violaxanthin, and zeaxanthin in YC differentiate this group from the RC group. Relative quantification was carried out to further analyze this aspect. 


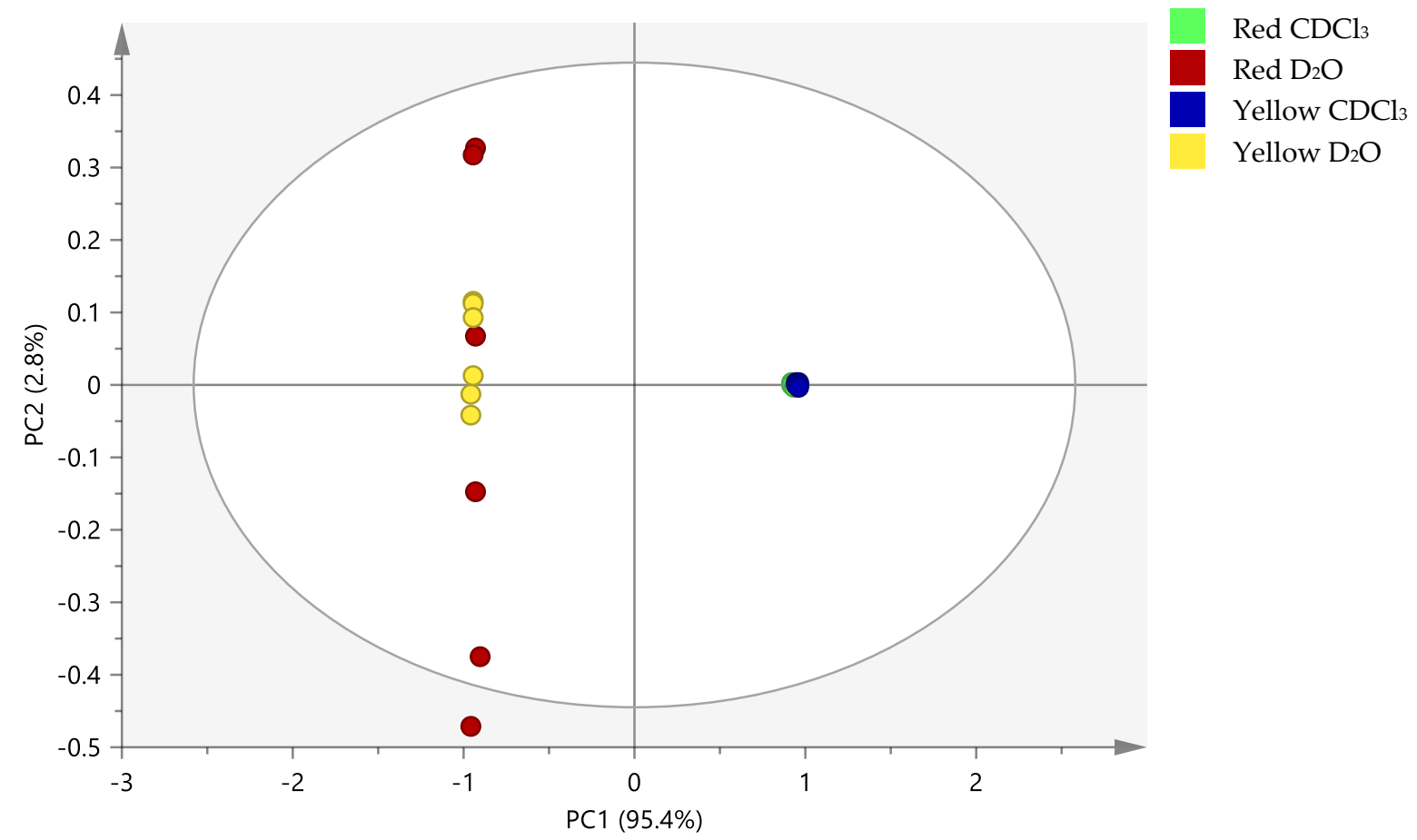

Figure 3. The principal component analysis (PCA) score plot of the ${ }^{1} \mathrm{H}-\mathrm{NMR}$ data representing red and yellow watermelon cultivars in two different solvents $\left(\mathrm{D}_{2} \mathrm{O}\right.$ and $\left.\mathrm{CDCl}_{3}\right) ; \mathrm{R} 2 \mathrm{X}=0.991, \mathrm{Q} 2 \mathrm{X}=0.983$, $n=6$.

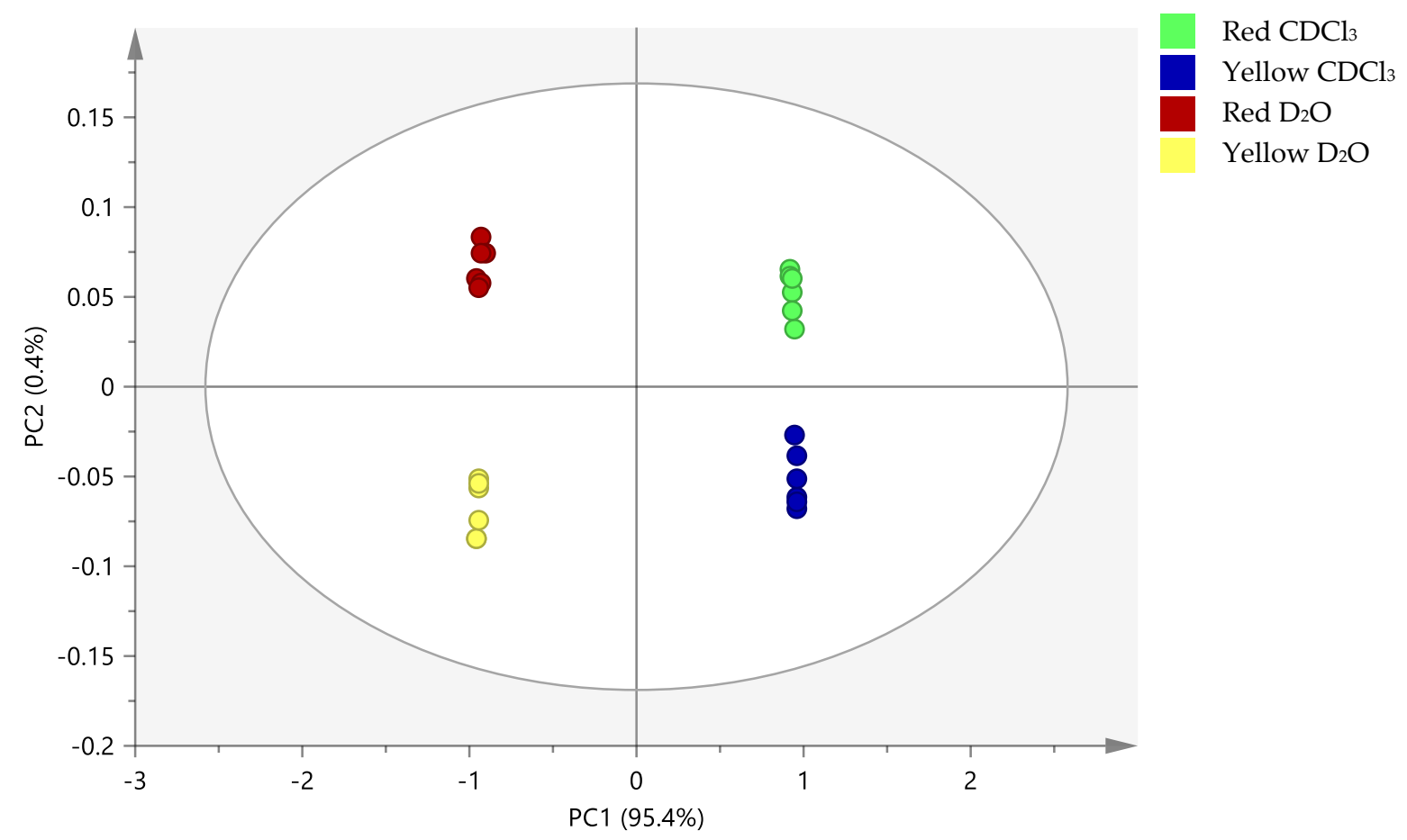

Figure 4. The orthogonal partial least squares discriminant analysis (OPLS-DA) score plot of the ${ }^{1} \mathrm{H}-\mathrm{NMR}$ data representing red and yellow watermelon cultivars in two different solvents $\left(\mathrm{D}_{2} \mathrm{O}\right.$ and $\left.\mathrm{CDCl}_{3}\right)$; $\mathrm{R} 2 \mathrm{X}=0.995, \mathrm{Q} 2 \mathrm{X}=0.862, n=6$.

\subsection{Relative Quantification}

Relative concentrations of metabolites with the variable importance in projection (VIP) value of more than 1 (Figure S10), which indicates those which have the most discriminatory attributes [35], 
was determined from the OPLS-DA. This was done to single out the metabolites responsible for class separation within the solvent group, which was not achieved using the PCA and OPLS-DA models. The mean peak area of characteristic ${ }^{1} \mathrm{H}-\mathrm{NMR}$ signals was chosen, and the chemical shifts selected included phenylalanine at $7.42 \mathrm{ppm}$, tryptophan at $7.3 \mathrm{ppm}$, tyrosine at $6.9 \mathrm{ppm}$, fumarate at $6.54 \mathrm{ppm}$, sucrose at $5.42 \mathrm{ppm}, \alpha$-glucose at $5.22 \mathrm{ppm}, \beta$-glucose at $4.62 \mathrm{ppm}$, malic acid at $4.34 \mathrm{ppm}$, fructose at $4.22 \mathrm{ppm}$, cucurbitacin E at $4.02 \mathrm{ppm}$, aspartate at $3.9 \mathrm{ppm}$, leucine at $3.7 \mathrm{ppm}$, xylose at $3.38 \mathrm{ppm}$, arginine at $3.22 \mathrm{ppm}$, aspartic acid at $2.66 \mathrm{ppm}, 4$-aminobutyrate at $2.3 \mathrm{ppm}$, glutamine at $2.14 \mathrm{ppm}$, citrulline at $1.58 \mathrm{ppm}$, alanine at $1.46 \mathrm{ppm}$, threonine at $1.34 \mathrm{ppm}$, gallic acid at $7.06 \mathrm{ppm}$, linoleic acid at $1.18 \mathrm{ppm}$, violaxanthin at $1.14 \mathrm{ppm}$, and zeaxanthin at $1.78 \mathrm{ppm}$.

The results, as shown in Figure 5, revealed that RW has higher concentrations of fumarate, $\alpha$-glucose, $\beta$-glucose, malic acid, xylose, arginine, 4-aminobutyrate, citrulline, alanine, and threonine, whereas YW has higher concentrations of phenylalanine, tryptophan, tyrosine, sucrose, fructose, cucurbitacin E, aspartate, leucine, aspartic acid, and glutamine. YC has higher relative concentrations of gallic acid, linoleic acid, violaxanthin, and zeaxanthin as compared to those in RC. Overall, the data closely resemble those predicted in the OPLS-DA loading column model, although only malic acid, citrulline, alanine, linoleic acid, and violaxanthin showed significant difference $(p<0.05)$ between both cultivars, as proven by the one-way ANOVA test.

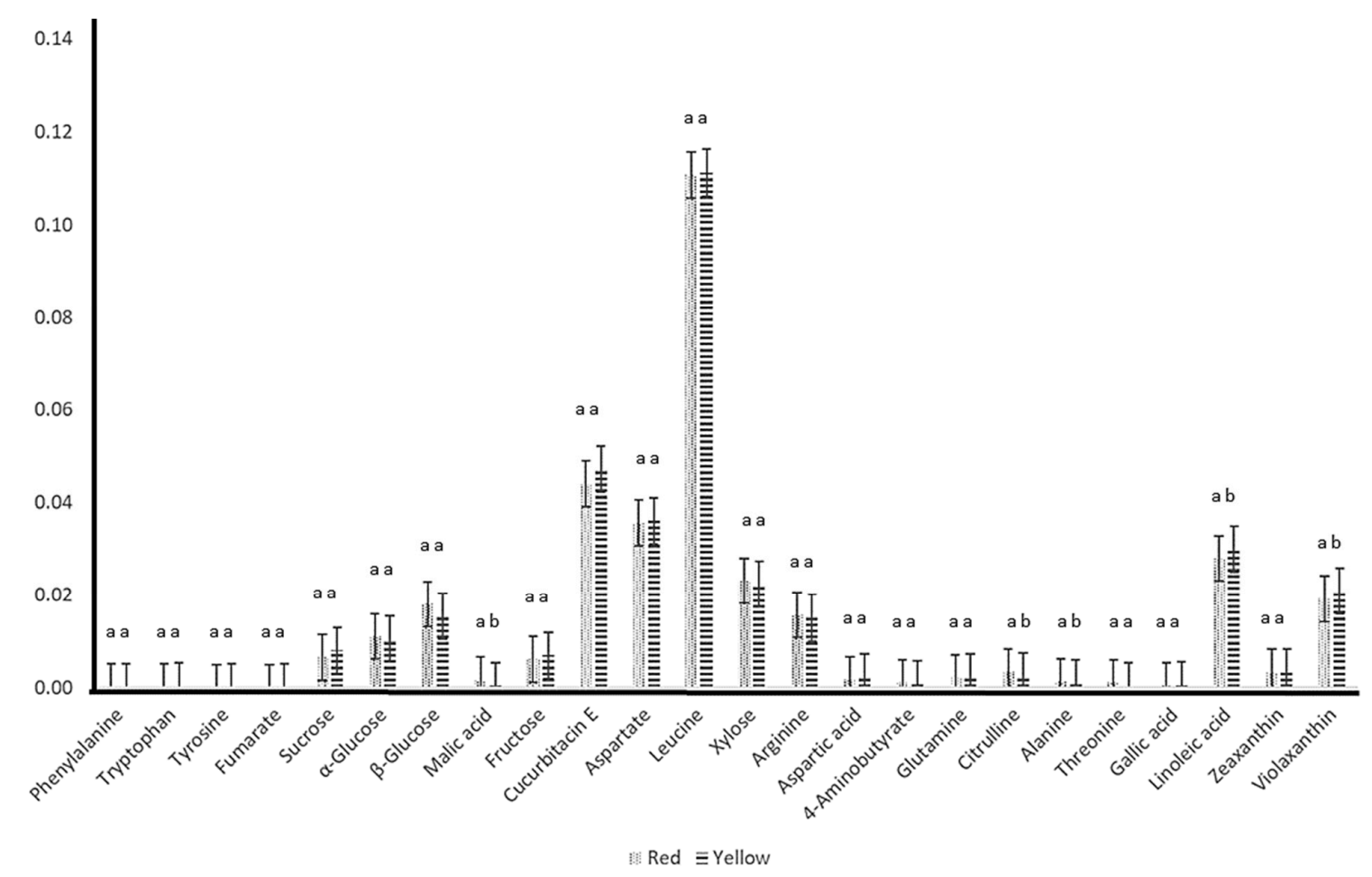

Figure 5. Relative quantification of the discriminatory metabolites identified from the yellow and red watermelon cultivars in $\mathrm{D}_{2} \mathrm{O}$ and $\mathrm{CDCl}_{3}$ solvents based on the mean peak area of the ${ }^{1} \mathrm{H}-\mathrm{NMR}$ signals. The different letters $(\mathrm{a}$ and $\mathrm{b})$ indicate significant difference $(p<0.05)$ between the two cultivars.

This study confirms the presence of widely studied phytoconstituents from the Citrullus lanatus species that are deemed as medicinally beneficial, such as lycopene, cucurbitacin E, citrulline, arginine, and ascorbic acid, among other metabolites [17,36,37]. Of these, lycopene and citrulline can be said to contribute significantly to setting the red watermelon cultivar apart from the yellow cultivar using a metabolomics approach, eventually making it a healthier dietary choice. However, the synergistic interaction between the metabolites must be taken into consideration as this can affect the bioavailability of the phytochemicals after ingestion and, therefore, influence their efficiency [38,39]. The use of less polar solvents for extraction coupled with other spectrometry tools (e.g., liquid chromatography-mass 
spectroscopy (LC-MS), gas chromatography-mass spectroscopy (GC-MS) and infrared spectroscopy) can be employed to improve the identification of less polar metabolites, such as the carotenoids and volatile compounds from both cultivars.

\section{Materials and Methods}

\subsection{Chemicals}

Deuterium oxide $\left(\mathrm{D}_{2} \mathrm{O}, 99.9 \%\right)$, deuterated chloroform $\left(\mathrm{CDCl}_{3}, 99.8 \%\right)$ with $0.03 \%$ tetramethylsilane (TMS), sodium deuterium oxide (NaOD), and potassium dihydrogenphosphate $\left(\mathrm{KH}_{2} \mathrm{PO}_{4}\right)$ were purchased from Merck (Darmstadt, Germany). 3-(Trimethylsilyl)propionic acid-d4 sodium salt (TSP) was obtained from Sigma-Aldrich (St. Louis, MO, USA).

\subsection{Plant Material}

The cultivation of red and yellow watermelons (Citrullus lanatus (Thunb.) Matsum. et Nakai) was carried out from March to May 2018 in Taman Pertanian Universiti (TPU: 2.986768, 101.70932) Universiti Putra Malaysia (UPM). The seeds were of F1 hybrid and procured from a local company (Green World Genetics Snd. Bhd.). The red watermelon is of the 310 variety (Red Rocky), while the yellow watermelon is of the 393 variety (Gold Dragon). The plants were grown organically; no pesticide was used at all growth stages and a combination of chopped grass and kale, animal waste, and earthworms was provided as fertilizer. Six each of the red and yellow watermelons were harvested at three months of age between 22 and 28 May 2018 and stored in a $-80{ }^{\circ} \mathrm{C}$ freezer immediately after harvested. On the processing day, the watermelon pulp was scooped out an inch away from the rind after the fruit was thawed to room temperature. The pooled pulp was deseeded and crushed to draw out the juice before it was subjected to continuous freeze-drying (Labconco, Kansas City, MO, USA) for three days. The powdered watermelon biomass was kept in a tightly sealed amber jar and stored in $-80{ }^{\circ} \mathrm{C}$ until further use.

\subsection{Extraction}

Watermelon water extract was prepared using the ultrasonication method [40,41]. Powdered biomass (10 g each) was weighed and dissolved in $200 \mathrm{~mL}$ Millipore water. The solution was subjected to sonication for $1 \mathrm{~h}$ at a temperature below $40{ }^{\circ} \mathrm{C}$. The extract was filtered using muslin cloth, and the residual pulp was extracted a second time using fresh Millipore water. The filtrate was pooled and freeze-dried (Labconco) to powder form before it was stored in a $-80{ }^{\circ} \mathrm{C}$ freezer. This process was repeated for all red and yellow watermelons, and the yield and water loss were calculated as shown in Table 2.

Table 2. Yield and water loss of the watermelon water extracts presented as means \pm standard deviation from six replicates. The different letters $(\mathrm{a}$ and $\mathrm{b})$ within the column indicate significant difference $(p<$ $0.05)$ between the two cultivars.

\begin{tabular}{ccc}
\hline Sample & Crude Extract Weight (g) & Water Loss (g) \\
\hline Red watermelon & $8.45 \pm 0.34^{\mathrm{a}}$ & $381.86 \pm 1.78^{\mathrm{a}}$ \\
Yellow watermelon & $9.18 \pm 0.07^{\mathrm{b}}$ & $380.05 \pm 1.88^{\mathrm{a}}$ \\
\hline
\end{tabular}

\subsection{NMR Analysis}

This method follows that outlined by the authors of [12] with some modifications. $\mathrm{KH}_{2} \mathrm{PO}_{4}$ buffer $(0.1 \mathrm{M})$ and an internal standard of $0.01 \%$ TSP were added to the $\mathrm{D}_{2} \mathrm{O}$ solvent, and the $\mathrm{pH}$ of the mixture was adjusted to 6.0 by carefully adding NaOD. Powdered extract $(50 \mathrm{mg}$ ) was dissolved in $1 \mathrm{~mL}$ of the buffered $\mathrm{D}_{2} \mathrm{O}$ and vortexed for $30 \mathrm{~s}$. The solution was sonicated in an ultrasonic bath for $5 \mathrm{~min}$ at a temperature below $40^{\circ} \mathrm{C}$ followed by centrifugation at 13,000 rpm for $10 \mathrm{~min}$. The supernatant of $600 \mu \mathrm{L}$ was transferred into a clean $5 \mathrm{~mm}$ NMR tube. The sample was subjected to ${ }^{1} \mathrm{H}-\mathrm{NMR}$ using $\mathrm{D}_{2} \mathrm{O}$ 
as an internal lock. This analysis was performed using a $500 \mathrm{MHz}$ Varian INOVA NMR spectrometer (Varian Inc., Palo Alto, CA, USA) at a frequency of $499.887 \mathrm{MHz}$ and a temperature maintained at $25^{\circ} \mathrm{C}$. The water peak was suppressed by applying a prestarvation (PRESAT) pulse sequence. The acquisition time of $3.53 \mathrm{~min}$ was required for 64 scans with a width of $20 \mathrm{ppm}$, a pulse width of $3.75 \mu \mathrm{s}$, and a relaxation delay of $1.0 \mathrm{~s}$ [42]. The internal standard (TSP) was calibrated to $0.00 \mathrm{ppm}$. This procedure was done on all 12 samples (6 each from the red and yellow watermelon water extracts) and later replicated using $\mathrm{CDCl}_{3}$ solvent with $0.03 \%$ TMS as an internal standard; the PRESAT step for this batch was omitted. The NMR analysis for each sample was done only once and a total of 24 spectra were obtained.

\subsection{Data Processing and Statistical Tests}

Microsoft Excel 2016 was used to perform the one-way analysis of variance (ANOVA) test at 95\% confidence interval to determine the significant difference between the variables. Phasing, alignment, and baseline correction of all spectra were completed using Chenomx software (v.5.1, Edmonton, AB, Canada). The ACSII files of the chemical shifts in the range of $\delta 0.3-10.0$ were binned at the spectral width of $\delta 0.04$ for all 24 spectra. The residual water peak between the region of $4.81-4.95 \mathrm{ppm}$ and the deuterated chloroform peak between the region of 7.25-7.27 ppm were excluded from this process. SIMCA-P software (v.14.1, Umetrics, Umeà, Sweden) with Pareto scaling was used to perform unsupervised principal component analysis (PCA) to better understand the similarities and differences of the metabolites from the two watermelon cultivars and the NMR solvents used. The model validation and significance were determined from the R2X and Q2X values. Supervised orthogonal partial least squares discriminant analysis (OPLS-DA) with 100-permutation and CV-ANOVA validation methods was used to further demarcate the groups.

\section{Conclusions}

The use of a chemometric tool is advantageous in studying closely related biological samples of the same species by means of metabolite distribution. This study proved the usefulness of ${ }^{1} \mathrm{H}-\mathrm{NMR}$ in the visualization of complex chemical data of two watermelon cultivars and their relatedness to the physical property of the fruits. By using metabolite profiling and MVDA, the red watermelon cultivar can be clustered apart from the yellow to determine the presence of lycopene and a high concentration of citrulline. The choice of two NMR solvents of different polarities was made to capture a wider group of metabolites from both polar and non-polar ends, although the latter, which harbors most of the carotenoids, is limited since the samples are derived from a more polar water extract. Future research on the incorporation of multiple spectrometric approaches with less polar solvents can be developed to streamline the metabolite identification step in order to better discriminate the two cultivars.

Supplementary Materials: The following are available online, Figure S1: Stacking of representative ${ }^{1} \mathrm{H}-\mathrm{NMR}$ spectra of red watermelon in $\mathrm{D}_{2} \mathrm{O}(\mathrm{RW})$, yellow watermelon in $\mathrm{D}_{2} \mathrm{O}(\mathrm{YW})$, red watermelon in $\mathrm{CDCl}_{3}(\mathrm{RC})$, and yellow watermelon in $\mathrm{CDCl}_{3}(\mathrm{YC})$, Figure S2: DModX plot; the circle showing the position of the outlier from the principal component analysis (PCA) score plot, Figure S3: Hotelling's T2 plot; the circle showing the position of the outlier from the principal component analysis (PCA) score plot, Figure S4: The orthogonal partial least squares discriminant analysis (OPLS-DA) score plot of ${ }^{1} \mathrm{H}-\mathrm{NMR}$ data representing red and yellow watermelon cultivars in $\mathrm{D}_{2} \mathrm{O} ; \mathrm{R} 2 \mathrm{X}=0.996, \mathrm{Q} 2 \mathrm{X}=0.986, n=6$, Figure S5: The orthogonal partial least squares discriminant analysis (OPLS-DA) score plot of ${ }^{1} \mathrm{H}-\mathrm{NMR}$ data representing red and yellow watermelon cultivars in $\mathrm{CDCl}_{3}$; $\mathrm{R} 2 \mathrm{X}=0.981, \mathrm{Q} 2 \mathrm{X}=0.953, n=6$,Figure S6: Permutation plot of orthogonal partial least squares discriminant analysis (OPLS-DA) model describing the Y-intercept of R2 (0.345) and Q2 (-0.754) for RW samples, Figure S7: Permutation plot of orthogonal partial least squares discriminant analysis (OPLS-DA) model describing the Y-intercept of R2 (0.333) and Q2 (-0.822) for YW samples, Figure S8: Permutation plot of orthogonal partial least squares discriminant analysis (OPLS-DA) model describing the Y-intercept of R2 (0.324) and Q2 (-0.795) for RC samples, Figure S9: Permutation plot of orthogonal partial least squares discriminant analysis (OPLS-DA) model describing the Y-intercept of R2 (0.349) and Q2 (-0.811) for YC samples, Table S1: CV-ANOVA validation test for orthogonal partial least squares discriminant analysis (OPLS-DA) score plot, Figure S10: Variable important in projection (VIP). 
Author Contributions: Conceptualization of the study and experimental design, I.S.I. and S.F.; plant material preparation and NMR analysis, F.S., A.A.A., Y.X.L., A.A.I. and I.S.I.; data interpretation, data analysis, manuscript writing and editing, F.S., I.S.I., S.F., S.M.M.F., F.A., A.A.A., and M.S.A.B. All authors have read and agreed to the published version of the manuscript.

Funding: This research is funded by Fundamental Research Grant Scheme (Project No. 01-01-18-2023FR) from the Ministry of Higher Education (MOHE), Malaysia.

Acknowledgments: We would like to thank Salahudin Mohd Raof of the Spectroscopy Unit and Azizul Isha of the Phytochemistry Unit, Laboratory of Natural Products, Institute of Bioscience, Universiti Putra Malaysia for the assistance given while conducting the experiments.

Conflicts of Interest: The authors declare no conflict of interest.

\section{References}

1. Biancolillo, A.; Marini, F. Chemometric methods for spectroscopy-based pharmaceutical analysis. Front. Chem. 2018, 6, 1-14. [CrossRef] [PubMed]

2. Bailey, N.J.C.; Oven, M.; Holmes, E.; Nicholson, J.K.; Zenk, M.H. Metabolomic analysis of the consequences of cadmium exposure in Silene cucubalus cell cultures via ${ }^{1} \mathrm{H}$ NMR spectroscopy and chemometrics. Phytochem. 2003, 62, 851-858. [CrossRef]

3. Quinta, G.; Garc1, J.C.; Agustı, A.F. Chemometric approaches to improve PLSDA model outcome for predicting human non-alcoholic fatty liver disease using UPLC-MS as a metabolic profiling tool. Metabolomics 2012, 8, 86-98. [CrossRef]

4. Amorello, D.; Orecchio, S.; Pace, A.; Barreca, S. Discrimination of almonds (Prunus dulcis) geographical origin by minerals and fatty acids profiling. Nat. Prod. Res. 2016, 30, 2107-2110. [CrossRef]

5. Socaci, S.A.; Socaciu, C.; Tofan, M.; Pintea, A. Chemometric discrimination of different tomato cultivars based on their volatile fingerprint in relation to lycopene and total phenolics content. Phytochem. Anal. 2014, 25, 161-169. [CrossRef] [PubMed]

6. Fiehn, O. Metabolomics - the link between genotypes and phenotypes. Plant. Mol. Biol. 2002, 48, $155-171$. [CrossRef] [PubMed]

7. Choi, Y.H.; Kim, H.K.; Linthorst, H.J.; Hollander, J.G.; Lefeber, A.W.; Erkelens, C.; Nuzillard, J.; Verpoorte, R. NMR metabolomics to revisit the tobacco mosaic virus infection in Nicotiana tabacum leaves. J. Nat. Prod. 2006, 69, 742-748. [CrossRef]

8. Widarto, H.T.; Van Der Meijden, E. Metabolomic differentiation of Brassica rapa following herbivory by different insect instars using two-dimensional nuclear magnetic resonance spectroscopy. J. Chem. Ecol. 2006, 32, 2417-2428. [CrossRef]

9. Besse, P. Molecular Plant. Taxonomy, 1st ed.; Humana Press: New York, NY, USA, 2014; pp. 1-38.

10. Hu, C.; Shi, J.; Quan, S.; Cui, B.; Kleessen, S.; Nikoloski, Z.; Tohge, T.; Alexander, D.; Guo, L.; Lin, H.; et al. Metabolic variation between japonica and indica rice cultivars as revealed by non-targeted metabolomics. Sci. Rep. 2014, 4, 1-10. [CrossRef]

11. Fujimura, Y.; Kurihara, K.; Ida, M.; Kosaka, R.; Miura, D. Metabolomics-driven nutraceutical evaluation of diverse green tea cultivars. PLoS ONE 2011, 6, 1-16. [CrossRef]

12. Kim, H.K.; Choi, Y.H.; Verpoorte, R. NMR-based metabolomic analysis of plants. Nat. Protoc. 2010, 5, 536-549. [CrossRef] [PubMed]

13. Verpoorte, R.; Choi, Y.H.; Kim, H.K. NMR-based metabolomics at work in phytochemistry. Phytochem. Rev. 2007, 6, 3-14. [CrossRef]

14. Ardenkjaer-Larsen, J.H.; Boebinger, G.S.; Comment, A.; Duckett, S.; Edison, A.S.; Engelke, F.; Griesinger, C.; Griffin, R.G.; Hilty, C.; Maeda, H.; et al. Facing and overcoming sensitivity challenges in biomolecular NMR spectroscopy. Angew. Chem. Int. Ed. 2015, 54, 9162-9185. [CrossRef] [PubMed]

15. Jolliffe, I.T.; Cadima, J. Principal component analysis: A review and recent developments. Phil. Trans. R. Soc. 2016, 374, 1-16. [CrossRef] [PubMed]

16. Worley, B.; Powers, R. Multivariate analysis in metabolomics. Curr. Metab. 2015, 1, 92-107.

17. Abdelwahab, S.I. Anti-inflammatory activities of cucurbitacin E isolated from Citrullus lanatus var. citroides: Role of reactive nitrogen species and cyclooxygenase enzyme inhibition. Fitoterapia 2011, 82, 1190-1197. [CrossRef] 
18. Tlili, I.; Hdider, C.; Salvatore, M.; Ilahy, R.; Jebari, H.; Dalessandro, G. Bioactive compounds and antioxidant activities during fruit ripening of watermelon cultivars. J. Food Compos. Anal. 2011, 24, 923-928. [CrossRef]

19. Johnson, E.J. The role of carotenoids in human health. Nutr. Clin. Care 2002, 5, 56-65. [CrossRef]

20. Lv, P.; Li, N.; Liu, H.; Gu, H.; Zhao, W. Changes in carotenoid profiles and in the expression pattern of the genes in carotenoid metabolisms during fruit development and ripening in four watermelon cultivars. Food Chem. 2015, 174, 52-59. [CrossRef]

21. Jayaprakasha, G.K.; Patil, B.S. A metabolomics approach to identify and quantify the phytochemicals in watermelons by quantitative ${ }^{1} \mathrm{HNMR}$. Talanta 2016, 153, 268-277. [CrossRef]

22. Tarachiwin, L.; Masako, O.; Fukusaki, E. quality evaluation and prediction of Citrullus lanatus by ${ }^{1} \mathrm{H}$ NMR-based metabolomics and multivariate analysis. J. Agric. Food Chem. 2008, 56, 5827-5835. [CrossRef] [PubMed]

23. Stahl, W.; Sies, H. Bioactivity and protective effects of natural carotenoids. Biochim. Biophys. Acta 2005, 1740, 101-107. [CrossRef] [PubMed]

24. Perkins-Veazie, P.; Collins, J.K.; Davis, A.R.; Roberts, W. Carotenoid content of 50 watermelon cultivars. J. Agric. Food Chem. 2006, 54, 2593-2597. [CrossRef] [PubMed]

25. Liu, C.; Zhang, H.; Dai, Z.; Liu, X.; Liu, Y.; Deng, X.; Chen, F.; Xu, J. Volatile chemical and carotenoid profiles in watermelons [Citrullus vulgaris (Thunb.) Schrad (Cucurbitaceae)] with different flesh colors. Food Sci. Biotechnol. 2012, 21, 531-541. [CrossRef]

26. Bang, H.; Davis, A.R.; Kim, S.; Leskovar, D.I.; King, S.R. Flesh color inheritance and gene interactions among canary yellow, pale yellow, and red watermelon. J. Amer. Soc. Hort. Sci. 2010, 135, 362-368. [CrossRef]

27. U.S. Department of Agriculture. Available online: https:/fdc.nal.usda.gov/fdc-app.html\#/food-details/ 786754/nutrients (accessed on 29 April 2020).

28. Tiziani, S.; Schwartz, S.J.; Vodovotz, Y. Profiling of carotenoids in tomato juice by one- and two-dimensional NMR. J. Agric. Food Chem. 2015, 54, 6094-6100. [CrossRef]

29. Mercadante, A.Z.; Britton, G.; Rodriguez-Amaya, D.B. Carotenoids from yellow passion fruit (Passiflora edulis). J. Agric. Food Chem. 1998, 46, 4102-4106. [CrossRef]

30. Azizan, A.; Ahamad Bustamam, M.S.; Maulidiani, M.; Shaari, K.; Ismail, I.S.; Nagao, N.; Abas, F. Metabolite Profiling of the microalgal diatom Chaetoceros Calcitrans and correlation with antioxidant and nitric oxide inhibitory activities via ${ }^{1} \mathrm{H}$ NMR-based metabolomics. Mar. Drugs 2018, 16, 154. [CrossRef]

31. Eh, A.L.; Teoh, S. Novel modified ultrasonication technique for the extraction of lycopene from tomatoes. Ultrason. Sonochem. 2012, 19, 151-159. [CrossRef]

32. Yusof, N.A. Infrared-metabolomics approach in detecting changes in Andrographis paniculata metabolites due to different harvesting ages and times. J. Sci. Food Agric. 2015, 95, 2533-2543. [CrossRef]

33. Pariyani, R.; Ismail, I.S.; Azam, A.A.; Abas, F.; Shaari, K. Identification of the compositional changes in Orthosiphon stamineus leaves triggered by different drying techniques using ${ }^{1} \mathrm{H}$ NMR metabolomics. J. Sci. Food Agric. 2017, 97, 4169-4179. [CrossRef] [PubMed]

34. Eriksson, L.; Johansson, E.; Kettaneh-Wold, N.; Trygg, J.; Wikström, C.; Wold, S. Multi- and Megavariate Data Analysis. Part 1: Basic Principles and Applications; Umetrics Academy Press: Umeå, Sweden, 2006.

35. Ginsburg, S.; Tiwari, O.; Kurhanewicz, J. Variable ranking with PCA: Finding multiparametric MR imaging markers for prostate cancer diagnosis. In Prostate Cancer Imaging. Image Analysis and Image-Guided Interventions, Proceedings of the International Workshop on Prostate Cancer Imaging, Toronto, Canada, 22 September 2011; Madabhushi, A., Dowling, J., Huisman, H., Barratt, D., Eds.; Springer-Verlag: Berlin/Heidelberg, Germany, 2011; pp. 146-157.

36. Ilahy, R.; Tlili, I.; Siddiqui, M.W.; Hdider, C.; Lenucci, M.S. Inside and beyond color: Comparative overview of functional quality of tomato and watermelon fruits. Front. Plant. Sci 2019, 10, 1-26. [CrossRef] [PubMed]

37. Collins, J.K.; Wu, G.; Perkins-Veazie, P.; Spears, K.; Claypool, P.L.; Baker, R.A.; Clevidence, B.A. Watermelon consumption increases plasma arginine concentrations in adults. Nutrition 2007, 23, 261-266. [CrossRef] [PubMed]

38. Commisso, M.; Bianconi, M.; Di Carlo, F.; Poletti, S.; Bulgarini, A.; Munari, F.; Negri, S.; Stocchero, M.; Ceoldo, S.; Assfalg, M.; et al. Multi-approach metabolomics analysis and artificial simplified phytocomplexes reveal cultivar-dependent synergy between polyphenols and ascorbic acid in fruits of the sweet cherry (Prunus avium L.). PLoS ONE 2017, 12, 1-23. [CrossRef] [PubMed] 
39. Faulks, R.M.; Southon, S. Challenges to understanding and measuring carotenoid bioavailability. Biochim. Biophys. Acta 2005, 1740, 95-100. [CrossRef]

40. Hong, X.; Isa, N.M.; Fakurazi, S.; Ismail, I.S. Phytochemical and anti-inflammatory properties of Scurrula ferruginea (Jack) Danser parasitising on three different host plants elucidated by NMR-based metabolomics. Phytochem. Anal. 2020, 31, 15-27. [CrossRef] [PubMed]

41. Yang, B.; Wang, J.; Zhao, M.; Liu, Y.; Wang, W.; Jiang, Y. Identification of polysaccharides from pericarp tissues of litchi (Litchi chinensis Sonn.) fruit in relation to their antioxidant activities. Carbohydr. Res. 2006, 341, 634-638. [CrossRef]

42. Maulidiani, M. Differentiation of Nigella sativa seeds from four different origins and their bioactivity correlations based on NMR-metabolomics approach. Phytochem. Lett. 2015, 13, 308-318. [CrossRef]

Sample Availability: Sample from the compounds are not available from the authors.

(C) 2020 by the authors. Licensee MDPI, Basel, Switzerland. This article is an open access article distributed under the terms and conditions of the Creative Commons Attribution (CC BY) license (http://creativecommons.org/licenses/by/4.0/). 